\title{
Influence of Cognitive Style and Gender on Secondary School Students' Achievement in and Attitude to Chemistry
}

\author{
Mabel. I. Idika \\ Department of Teacher (Science) Education \\ Faculty of Education, University of Ibadan \\ Ibadan, Oyo State, Nigeria.
}

\begin{abstract}
The purpose of the study was to determine the influence of two major cognitive styles (Field Dependent and Field independent) and gender on students' achievement in and attitude to chemistry. A total of two hundred and eight (208) SSII chemistry students drawn from some selected secondary schools in three local government areas in Ibadan, Oyo state, Nigeria participated in the study. Three instruments were employed in this research. They are Cognitive Style Checklist $(r=0.84)$, Chemistry Achievement Test(r=0.81) and Students' Attitude to Chemistry Questionnaire(r=0.84). This was a survey research. Four hypotheses were tested at 0.05 level of significance and data collected were analyzed using Descriptive Statistics and t-test. The results showed that there was significant main difference between on field dependent and field independent students' achievement in chemistry $(t(1,207)=5.173 ; P<0.05]$; students with field independent level of cognitive style obtained higher mean score of chemistry achievement ( = 8.89) than those with field dependent level of cognitive style $(=8.19)$; there was no significant main difference between field dependent and field independent students' attitude to chemistry $[t(1,207)=1.271 ; P>0.05]$; there was no significant main difference between male and female students' achievement in chemistry $[t(1,207)=.704 ; P>.05]$ but the female students obtained higher mean achievement score $(=98.64)$ than their male counterparts $(=98.28)$; there was significant main difference between male and female students' attitude to chemistry $[t(1,207)=18.041 ; P<0.05]$. Cognitive style can affect students' achievement in chemistry and those of the field independent category perform better than those of the field dependent category; whereas, cognitive style has no influence on students' attitude to chemistry. Even though, male and female students do not differ much in their achievement in chemistry, their attitude of the female students to chemistry is better than that of the male students. Therefore, it is recommended that teachers have adequate knowledge of the dominant cognitive style category in their classes as this could facilitate and ensure more meaningful learning as well as serve as guide for selection of teaching methods. In addition, chemistry teachers should make efforts in ensuring that chemistry classes are interesting and appealing to their male students.
\end{abstract}

\section{INTRODUCTION}

Chemistry serves as an avenue for a student to imbibe scientific attributes such as objectivity, critical reasoning and problem-solving. A good knowledge of chemistry demystifies certain issues in life that may appear as odd to us. It eliminates superstition. Summarily, chemistry is a very crucial aspect of science, education and life as a whole. Therefore, every nation must give high level of priority to the subject and its study. Despite much efforts made to ensure that students perform well in chemistry, reports from the WAEC Chief Examiner (May/June, 2005, 2008 \& 2009 ) show a trend of poor results. While this has been attributed to shallow knowledge of the subject, Adesoji and Olatunbosun (2008) in a research on the effect of some factors on students' achievement in chemistry, stated that in spite of the attempts made by 
researchers to improve on the teaching and learning of chemistry, the achievement of students in the subject remains low in Nigeria.

Broadly speaking, many factors have been shown to have significant impact on students learning outcomes in chemistry. One of the categories of factors is the student factor or learner factor(Korau (2006) cited in Nbina,2012). The learner, himself is a central factor in determining whether meaningful learning will take place or not. This may include his background, motivation, age, sex or gender, personality, cognitive style and so on(Tai, Sadler and Loehr(2005), Ogunleye(2011), Alavi and Hoseini, 2009, Bassey, Umoren and Udida,2013 )

According to Miller (1987) cognitive styles represent the individual differences in the various subcomponents of an information-processing model of three main cognitive processes: perception, memory, and thought. He argued that "all of the cognitive styles are subordinate to, and reflect, a broad super ordinate stylistic (analytic-holistic) difference".

Riding and Cheema's (1991) developed an integrative model of cognitive styles after examining over 30 style labels in the literature based on the descriptions, correlations, methods of assessment, and effects on behavior of these style labels. The researchers concluded that they could be grouped into two major cognitive styles: wholist-analytic and verbal-imagery. The former concerns whether an individual tends to process information in wholes or in parts; the latter pertains to whether an individual has a propensity to signify information while thinking verbally or one does so in mental pictures.

The final and most recent endeavor in integrating works on styles is Stemberg's (1997) model. According to Stemberg, works on styles fall into one of the three traditions: cognition centered, personality centered, and activity centered. Styles in the cognition-centered tradition most closely resemble abilities (Zhang,2004).

Cognitive style is considered to be a personality dimension that influences attitudes, values, and social interaction. Cognitive skills are multi-dimensional. Two major dimensions have been drawn out by Riding and Sadler-Smith(1997). They are Verbaliser/Imager and Wholistic/Analytic dimensions. The former dimension categorizes learner according to their usual way of representing information in memory. While Verbalisers consider the information they read, see or listen to in words or verbal relationships, Imagers experience "fluent, spontaneous, and frequent pictorial mental pictures". Cognitive styles have been studied extensively since the 1970s in an attempt to understand the varying ways that learners perceive and interact with instructional settings, methods, and media.

The most widely investigated cognitive style is Herman Witkin's field dependence/independence(DeTure, 2004) This dimension is based on Field Dependence, that is, the degree to which an individual is able to distinguish and to separate elements embedded in complex settings. Calcaterra et al, 2005 established that the field dependence dimension of categorizing cognitive styles is very similar and related to analytical-sequential and wholisticintuitive style dimension.

Field-dependent learners process information overall and rely more on external reference. They succeed in situations where structure is provided for them and tend to solve problems through intuition and trial-and-error approaches whereas Field-independent personalities approach the environment in a highly analytical manner such as making out figures as discrete from their surroundings. The mental schemas of this set of people entail multiple accessibility 
of components and varied relations between them. They tend to actively frame their own learning by perceiving objects as whole and by investigating the underlying causal relationships of problem situations (Calcaterra, 2005).

Table 2.2 is a summary of the differences between the two levels of the Field-Dependence dimension of cognitive style:

Table 2.2

\begin{tabular}{|c|c|}
\hline FIELD DEPENDENT(FD)(non-analytic) & FIELD INDEPENDENT(FI)(analytic) \\
\hline Have comprehensive perceptions & Excellent at analytical thinking \\
\hline $\begin{array}{l}\text { Perceive objects as a whole and approach a } \\
\text { task more holistically }\end{array}$ & $\begin{array}{l}\text { Focus on individual parts of the object and } \\
\text { tend to be more serialistic in their approach to } \\
\text { learning }\end{array}$ \\
\hline Rely 1 & Rely more on internal references \\
\hline More influe & Less affec \\
\hline More reliant on salient cues in lear & $\begin{array}{l}\text { Tend to sample more cues inherent in the field } \\
\text { and are able to extract the relevant cues } \\
\text { necessary for the completion of a task. }\end{array}$ \\
\hline Likely & Likely to use passive cognitive stra \\
\hline Adopt a hy & ctator role in learning \\
\hline Likely to benefit from a self-direc & $\begin{array}{l}\text { Tend to prefer more structured learning } \\
\text { environments }\end{array}$ \\
\hline Self-vic & e of separate identity \\
\hline $\begin{array}{l}\text { Not well-skilled in social/interpersonal } \\
\text { relationships }\end{array}$ & $\begin{array}{l}\text { Highly skilled in interpersonal/social } \\
\text { relationships }\end{array}$ \\
\hline
\end{tabular}

Wyss (2002), Chen and McCredie, (2004)

As a widely researched cognitive style, the field dependence-independence construct describes two different ways of information processing. Individuals are positioned along a continuum running from extreme field-dependence (FD) to extreme field-independence (FI). Those located towards the FD end of the continuum are limited in their propensity to separate information from its contextual surroundings whereas FI individuals have little or no difficulty in carrying out same task (Guisande, Paramo, Tinajero and Almeida, 2007). Cognitive styles are not affected by intelligence and Field Dependence/Independence focuses on the process of learning rather than ability (Maghsudi, 2007). Robert Wyss (2002) presented a checklist that can enable students recognize their cognitive style.

Calcaterra, Antonetti and Underwood (2005) and DeTure (2004) found from their studies that cognitive style had no significant effect on learning outcomes and that it was a poor predictor of success in learning. Elsewhere, Kirk (2000) showed that field independence has significant correlation with academic achievement.

Zwane and Dlamini (1999) assert that students' performance can be affected by several factors and one of them they say is sex, otherwise referred to as gender. Despite the fact that many researchers have worked extensively on the issue of gender and its influence on students' performance, one can state here that the results are fairly inconclusive and contrasting. Gender is both a biological and social construct that simply categorizes individuals as male or female. Gender issues have been a topic that has enjoyed vigorous and enormous attention from researchers from all fields in the academics. In many cases, the findings are hardly conclusive. 
Part of the debate over the years has been centered on the influence gender has on a learner's academic performance as well as his or her disposition to learning. One school of thought reported that males do better than females (Bolger and Kellaghan, 1990; Vogel, 1990; Marx and Klinger, 2000). Eraikhuemen (2003) also found that male senior secondary school students scored higher in achievement than their female colleagues.

However, other results convey a contrary view, implying that females tend to perform better than males in academic achievement (Deary, 2007).In support of this, reports from the National Assessment of Education Progress(2009) as well as Programme for International Student Assessment(PISA) established that female students scored higher than boys in Standardized tests, Reading and Writing(Watson,2010). In a research involving the use of Mental Rotation to manipulate stereotypes, Moe (2009) showed that women's performance could improve when they are led to think and believe that they were better than men. In a similar experiment, Stoet and Geary (2012) showed that females who were told that men and women performed equally expressed outcomes that were not different from that of their male counterparts.

In her work on the effect of gender on achievement in chemistry, Okereke(2011) showed that male students achieved significantly better than female students and that gender need not be an obstacle in the use of innovative teaching strategies in science classes. Many studies show that male students consistently achieve higher than their female counterparts in science (Okonkwo and Eke,2005, Njoku, 2007, Okigbo, Akusoba,2009 in Okereke, 2011).Stereotype threat has been found to impair cognitive abilities. Researcher say that this uncomfortable psychological state also impairs behavior that develop individuals' ability to learn science and technology(Appel, 2011) Another researcher's result showed that children did achieve better at tasks labeled as Sex-appropriate(Davies,2011).

While, examining the differential effects on the achievement of males and females of teaching the particulate nature of chemistry, Bunce and Gabel (2002) found no significant difference between the females and the males who were subjected to treatment. This is in line with the work of Wachanga and Mwangi (2004), Alavi and Hoseini( 2009) and Achor, Kurumeh and Orokpo(2012) who also found that gender did not affect achievement nor did it predict males' or females' achievement in chemistry. Another researcher's study failed to find any difference between boys and girls nor interaction between treatment and gender with respect to students' understanding of atom concept, learning approaches, motivational goals, self-efficacy, epistemological beliefs (Caliskan, 2004).

Attitude is one of the vital determinants of an individual's actions. Although there are many definitions of attitude, all the views agree that an attitude is an individual's disposition to think, feel, or act positively or negatively toward objects in his environment. Attitude has also been viewed as a non-observable psychological unit that can only be deduced from an expressed behavior, embracing a range of emotional behaviors such as "prefer", "accept"," appreciate" and so on( Adolpe,2002,Welch,2010)

In the past years, Social psychologists have long addressed attitudes as having three components: the cognitive, the affective, and the behavioral. The cognitive component is a set of ideas or convictions about the attributes of the object and its assessment is carried out in written forms or questionnaires). The affective component involves the individual's feelings about the object and it is assessed using psychological indices such as facial expressions, body language, heart rate, e.t.c. The behavioral component pertains to the way people act toward the 
object and its assessment is performed with directly observed behaviors (Salta and Tzougraki, 2004).

Attitudes associated with science appear to affect students' participation in science as a subject and impact performance in science. A positive attitude to science can elicit learner's interest in science education and careers that require the knowledge of science (Jegede, 2007). It is known that teacher's approach or technique within and without the classroom can influence students' learning either negatively or positively (Ikejiaku, 2006). Students need to have the right attitude in order for meaningful learning to take place. An international assessment of nine and thirteen-year old students in twenty countries as reported by the International Assessment of Educational Progress (1992) showed that positive attitudes toward science affect students' learning outcomes. In addition, a research examining psychological effects found that a student's self-concept of his ability to perform in science positively correlated with achievement (Oliver and Simpson, 1988, Jegede, 2007).

Existing literature reveals differing views on the influence of student's cognitive style and gender on learning outcomes in chemistry. Hence, this research survey is an attempt to contribute to the wide scope of this field considering the students in Ibadan, Oyo state, Nigeria.

\section{Hypotheses}

H01: There is no significant main difference between Field dependent and Field independent students' Achievement in Chemistry

H02: There is no significant main difference between Field dependent and Field independent students' Attitude to Chemistry

H03: There is no significant main difference between Male and Female students' Achievement in Chemistry

H04: There is no significant main difference between Male and Female students' Attitude to Chemistry

\section{Scope and Limitation of the Study}

The study covered Senior Secondary class Two (2) students from six (6) schools in three (3) Local Government Areas in Ibadan, Oyo State, Nigeria.

\section{METHODOLOGY}

The sample consisted of two hundred and eight (208) SSII chemistry students drawn from three (3) Local Government Areas in Ibadan, Oyo State and intact classes in six (6) senior secondary schools were purposively selected. Selection of school was based on the following criteria:

a) The school must be a co-educational secondary school

b) The school must have a sizeable number of students offering chemistry

c) The school has at least one graduate Chemistry teacher teaching SSII students

\section{INSTRUMENTS}

Three instruments were used in this study. They are:

\section{Cognitive Style Checklist (CSC)}

The Cognitive Style Checklist (CSC) was developed and used by a University professor, Robert Wyss(2002) in his work on Field dependence/Independence and the learning of L2 language. The instrument consists of simple statements from which subjects in the research are to 
indicate the ones which apply to them. For the present study, the CSC was adapted, modified and revalidated for use in the researchers' academic field of interest.

The checklist was used to categorize the students based on their cognitive styles. Each of the 10 items is divided into two (2) sub-statements i.e. (A) or (B). Sub-statement A represents the characteristics of the Field independent while sub-statement B represents those of Field dependent. Students who indicate up to seven (7) A's are categorized as Field independent while the rest are regarded as Field dependent. The total time allotted for the list was 15 minutes.

The instrument was validated through test-retest haven shown it to experts in science education for construct and face validity. The instrument was further subjected to reliability test and an alpha value of 0.84 was obtained.

\section{Chemistry Achievement Test (CAT)}

It is a 25-item achievement test designed to measure the learners' achievement in Chemistry. CAT was validated through review by expert chemistry teachers. Their comments and corrections in terms of relevance of content, grammatical errors and simplicity of language were considered in the final design of CAT. This was then administered to 20 students at a neutral school which was not part of the research sample. The reliability co-efficient was computed using Kuder-Richardson formula 20 (KR 20).The reliability coefficient was 0.81 while the average item difficulty was 0.53 . The final 25 items were used as pre-test and posttest. It covered the different levels of cognitive development such as Knowledge

\section{Students' Attitude to Chemistry Questionnaire(SACQ)}

This is a 25 -item questionnaire on a four point Likert type odinal scale aimed at measuring students' affective domain on some issues relating to electrolysis. The instrument has two sections; A and B. Section A seeks the student's data such as name of school, sex and age. In section $B$, students are asked to read the statements carefully and indicate their responses by ticking any of the options such as strongly agree(SA),agree(A), disagree(D) or strongly disagree(SD).The questionnaire was administered both as pre-test and post-test. SACQ was validated by experts in psychology and colleagues. Their comments and corrections were used to make appropriate modifications on the instrument. The final draft was administered to 20 students who were not part of the research sample. Cronbach Alpha was used to calculate the reliability coefficient which was found to be 0.84 .

\section{Administration of Instruments}

The three instruments were administered on two separate days. On the first day, the SACQ was administered along with the CSC. The participants were encouraged to fill the forms with high sense of honesty. They were given 30 minutes for each of the instruments while on the second day, the CAT was administered.

\section{Data Analysis}

The data collected from the experiment were subjected to analysis using Descriptive statistics and $t$-test. All hypotheses were tested at 0.05 level of significance. 
RESULTS AND DISCUSSIONS

Table 1: $t$-test showing means difference between male and female achievement in chemistry

\begin{tabular}{|c|c|c|c|c|c|c|c|}
\hline Achievement & $\mathrm{N}$ & $\bar{x}$ & SD & $\mathrm{df}$ & $\mathrm{t}_{\mathrm{cal}}$ & $t_{\text {crit }}$ & Prob \\
\hline Male & 100 & 98.28 & 16.72 & \multirow{3}{*}{206} & \multirow{3}{*}{1.06} & \multirow{3}{*}{1.98} & \multirow{3}{*}{$\begin{array}{l}>.05 \\
\text { Not } \\
\text { Rejected }\end{array}$} \\
\hline Female & 108 & 98.64 & 24.17 & & & & \\
\hline Total & 208 & & & & & & \\
\hline
\end{tabular}

Not significant

FD - field dependent

FI - field independent

Table 1 shows that gender has no significant main influence on students' achievement. It is clear from the data analyzed that there is no significant main difference in the mean chemistry achievement scores of male and female students. This finding aligns with that of Adu (2002) who found that gender had no effect on achievement. This, however, is in contrast to the findings of Okereke (2011) and Eraikhumen (2003) which found that males outdid the females in achievement in Mathematics. Generally, the relationship between gender and academic achievement is inconclusive. It appears that the awareness concerning gender equality in education is closing up the gap between males and females.

Table 2: $\mathrm{t}$ - test showing means difference between male and female attitude scores in chemistry

\begin{tabular}{|c|c|c|c|c|c|c|c|}
\hline Attitude & $\mathbf{N}$ & $\bar{x}$ & SD & df & $\mathbf{t}_{\mathrm{cal}}$ & $\mathbf{t}_{\text {crit }}$ & Prob \\
\hline Male & 100 & 66.98 & 10.64 & \multirow{3}{*}{206} & \multirow{3}{*}{6.48} & \multirow{3}{*}{1.98} & \multirow{3}{*}{$\begin{array}{l}<\quad .05 \\
\text { Rejected }\end{array}$} \\
\hline Female & 108 & 70.64 & 8.16 & & & & \\
\hline Total & 208 & & & & & & \\
\hline
\end{tabular}

Significant 0.05

However, table ....... shows that there is significant main influence of gender on students' attitude $[\mathrm{t}(1,207)=18.041 ; \mathrm{P}<.05]$. This means that there is significant main difference in the male and female students' attitude to chemistry. This may be due to the fact that males and females feel and perceive things differently. In addition, Table...... further presents the magnitude of the mean scores of the female ( $=70.64)$ slightly higher than their male counterparts $(=66.98)$. This may also be due to the reason already stated above. This is in contrast with the results obtained from the work of Salta and Tzougraki(2004) who concluded that, although there were no significant differences between the attitudes of males and females towards chemistry but that girls held a less positive attitude than boys with regards to the difficulty of chemistry courses. Perhaps, this is due to the inquiry nature of chemistry. Females are more emotional, more detailed and more sensitive to new things than males. Females tend to be more vulnerable and more receptive to changes.

Table $3: \mathrm{t}$ - test showing means difference between field independent and field dependent in chemistry achievement

\begin{tabular}{|l|l|l|l|l|l|l|l|}
\hline Achievement & N & $\bar{x}$ & SD & df & $\mathbf{t}_{\text {cal }}$ & $\mathbf{t}_{\text {crit }}$ & Prob \\
\cline { 1 - 6 } & & & & & & & \\
\hline FI & 84 & 8.19 & 6.86 & 206 & 26.65 & 1.98 & $<.05$ \\
\hline
\end{tabular}

Significant 0.05 level of significance 
Results from Table 3 also showed that there is significant main influence of cognitive style on students' achievement $(\mathrm{t}(1,207)=5.173 ; \mathrm{P}<0.05]$. This means that there is significant difference in the chemistry achievement of students with field independent and field dependent cognitive style as is the finding of Bassey, Umoren and Udida (2013) whose results showed that students with analytical cognitive styles did better than those with relational and inferential cognitive styles. In each of the two dependent variables, however, students with field independent level of cognitive style performed better than their counterparts with field dependent level of cognitive style to chemistry.

This is in contrast with Maghsudi (2007) who concluded that cognitive styles are not affected by intelligence and that Field Dependence/Independence focuses on the process of learning rather than ability. Guisande,Paramo,Tinajero and Almeida(2007) seemed to agree with the findings of this work. This may be due to the fact that cognitive style describes how an individual accesses, perceives and processes information. The strategies used in the study were constructivist/inquiry based strategies and these strategies are basically learnercentered. Therefore, the effect of cognitive style on the students' achievement was detected.

Table 3 also revealed that students with field independent level of cognitive style to chemistry obtained higher mean score of chemistry achievement $(=8.89)$ than those with field dependent level of cognitive style to chemistry $(=8.19)$. This is in accord with the results obtained by Kirk (2000) and 0' Brein, Butler and Bernold(2001). Learning chemistry involves critical and deep thinking as well as display of initiative. Field independent individuals are excellent analytical thinkers who view things from a serialistic and detailed manner. The more field independent a student is, the more he or she is encouraged to achieve more meaningful learning.

Table 4: $\mathrm{t}$ - test showing means difference between field independent and field dependent in chemistry attitude

\begin{tabular}{|l|l|l|l|l|l|l|l|}
\hline Attitude & N & $\bar{x}$ & SD & df & $\mathbf{t}_{\text {cal }}$ & $\mathbf{t}_{\text {crit }}$ & Prob \\
\hline FD & 84 & 68.55 & 5.75 & 206 & 0.25 & 1.98 & $>.05$ \\
FI & 124 & 69.38 & 14.08 & & & & $\begin{array}{l}\text { Not } \\
\text { Reject }\end{array}$ \\
\hline
\end{tabular}

Not significant 0.00 significant level

Table 4 shows that there is no significant main influence of cognitive style on students' attitude to chemistry $[\mathrm{t}(1,207)=1.271 ; \mathrm{P}>0.05]$. This implies that both field independent and field dependent students do not differ significantly in their attitudes towards chemistry.

Even though the difference is not significant, Table 4 also shows that students with field independent level of cognitive style to chemistry obtained higher attitude score $(=69.36)$ than their counterparts with field dependent level of cognitive style to chemistry ( $=68.55)$. This is probably because the cognitive style checklist laid a lot more emphasis on the way the students receive and perceive information rather than how they process it. 


\section{SUMMARY OF FINDINGS}

1. There is significant main influence of cognitive style on students' achievement but there is no significant influence of cognitive style on students' attitude to chemistry. In each of the two dependent variables, however, students with field independent level of cognitive style performed better than their counterparts with field dependent level of cognitive style.

2. Gender has no significant main influence on students' achievement. On the other hand, gender has significant influence on students' attitude to chemistry. However, in both cases the female students' performed better than the male students.

\section{CONCLUSION AND RECOMMENDATIONS}

With respect to cognitive style, students that are field-independent did better in achievement than those that field dependent. Also, gender did not affect students' achievement but males and females differed in attitude to chemistry

It is therefore recommended that:

1. Students learn differently based on gender or cognitive style. Therefore, it is recommended that science teachers are adequately equipped with the skills needed to create an environment where all kinds of students can learn meaningfully individually or in groups especially in a chemistry class.

2. Educational policy makers should take into consideration the desperate need for better policy, regulations and laws that are geared toward the attainment of more meaningful chemistry education in Nigeria.

\section{References}

Achor, E. E., Kurumeh, S.M. and Orokpo, C. A. 2012 Gender Dimension in Predictors of Students' Performance in MOCK-SSCE Practical and Theory Chemistry Examinations in some Secondary Schools in Nigeria. Education 2(2): pp 16-22

Adesoji, F.A and Olatunbosun, S.M. 2008. Student, Teachers and School environment factors as Determinants of Achievement in Senior Secondary School Chemistry in Oyo State, Nigeria. The Journal of International Social Research Vol 1(2) pp 13-34.

Adolpe F. 2002. A Cross-national Study of Classroom Environment and Attitudes among JSS students in Australia an in Indonesia. Doctoral Dissertation, Curtin Univ. of Technology.

Adu, E. O. 2002 Two Problem-Based Learning Strategies Quantitative Ability and Gender as Determinants Of Student Academic Achievement In Economics. An unpublished PhD thesis. University of Ibadan, Ibadan.

Alavi, H. R. and Hoseini, A. R. 2009 The Effect of Educational Factors on the Academic Performance of the University Students in Chemistry. Chemical Education Journal (CEJ) Vol 13:2

Appel, M. 2011. Stereotype threat impairs ability building. Effects on test preparation among women in Science and technology. European Journal of Social Psychology Vol 41, Issue 7 pp904 -913.

Bassey, S. W., Umoren, G. and Udida, L. A. (2013) Cognitive Styles, Secondary School Students' Attitude and Academic Performance in Chemistry in Akwa Ibom State- Nigeria.www. hbcse.tifr.res.in/........../bassey

Bolger, N. and Kellaghan, T. 1990. Method of Measurement and Gender Differences in Scholastic Achievement. Journal of Educational Measurement Vol 27(2) pp 165 -174.

Bunce, D.M. and Gabel, D. 2002. Differential effects on the Achievement of Males and Female of teaching the Particulate nature of Chemistry Journal of Research in Science Teaching Vol. 39(10) pp 911 -927.

Calcateria, A., Antonetti, A. and Underwood, J. 2005. Cognitive Style, hypermedia navigation and Learning. Computer and Education Vol. 44 pp 441-457. 
Caliskan, I.S. 2004. The Effect of Inquiry -based Chemistry Course on Students' understanding of Atom Concept, Learning Approaches, Motivation, Self-Efficacy and Epistemological beliefs Published M.Sc Thesis in the Department of Secondary Science and Mathematics Education, The Middle East Technical University.

Chen, S.Y. and McCredie, R.D. 2004. Cognitive Modeling of Student Learning in web-based Instructional Programs. International Journal of Human-Computer Interaction. Vol.17(3) pp 375-402.

Davies, D.R. 2011. Children's Performance as a function of Ser-typed labels. British Journal of Social Psychology Vol 25 (2) pp. 173 -195.

Deary, I.J 2007. Intelligence and Educational Achievement. Intelligence Vol. 35 (1) pp 13-21.

De-ture, M. 2004. Cognitive Style and Self-Efficacy. The American Journal of Distance Education. Vol. 18(1) pp.2138.

Eraikhuemen, L. 2003. The Influence of Gender and School Location on Students'. Academic Achievement in Senior Secondary School Mathematics. Ife Journal of Theory and Research in Education Vol. 7(2) pp 99-112.

Guisande, M.A., Paramo, M.F., Tinajero, K.. and Almeida S.A. 2007. Field-dependence-independence (FDI) Cognitive Style: An analysis of attentional functioning Psicothema, Vol. 19(4) pp 572-577.

Ikejiaku, L.A. 2006. Psychology of Learning. Lagos.

Kirk, G. R. (2000) The Relationship of Attitudes towards science, cognitive styles and self-concept to achievement in chemistry at the secondary school level. DAI, 61(5), 1789-A

Maghsudi, M. 2007. The Interaction Between Field Dependent/Independent Learning Styles and Learners' Linguality in third Language Acquisition. Language in India Vol.7 pp. 1-16.

Marx and Klinger, D.A. 2000.Hierachical Linear Modeling of Student and School Effects on Academic Achievement Canadian Journal of Education. Vol. 25(1) pp 41-55.

Moe, A. 2009. Are males always better than females in mental rotation. Exploring a gender belief explanation Learning and Individual Differences. Vol 19(1) pp 21-27.

Nbina, J.B. 2012 Analysis of Poor Performance of Senior Secondary Students in Chemistry in Nigeria. African Research Review Vol 6(4) pp 324-334

O'Brein, T.P., Butler, S.M. and Bernold, L. E. 2001. Group Embedded Figures Test and acadaemic achievement in Engineering Education. Int. J. Engng Ed. Vol 47(1) pp 89-92

Okereke, C. 2011. Influence of Gender, School location and the use of play simulation on School Achievement in Chemistry. JORIND (9)1.

Ogunleye, B. 0. 2011 "Team Pair Solo" Cooperative Learning and Personality type as Determinants of Students' Achievement and Attitude to Chemistry. African Research Review. Vol 5(6) pp 259-276

Riding, R.J. and Sadler-Smith, E. 1997. Cognitive Style and Learning Strategies: Some Implications per training design International Journal of Training and Development Vol. (3) pp 199-208.

Salta, K. and Tzougraki, C. 2004. Attitudes towards Chemistry among 11th Grade Students' in High Schools in Greece. Sci Ed Vol. 88(4) pp. 531-547.

Stoet, G. and Deary, D.C. 2012. Can Stereotype threat explain the gender gap in Mathematics performance and achievement? Review of General Psychology, Vol 16 (1) pp. 93 -102.

Tai, R.H., Sadler, P.M. and Loehr, J. F. 2005 Factors influencing Success in Introductory College Chemistry. J. Res Sci Teach 42: 987-1012

Vogel, S.A. 1990. Gender differences in Intelligence, Language, Visual-Motor Abilities, and Academic Achievement in Students with Learning Disabilities: A Review of the Literature Journal of Learning Disabilities.

Wachanga, S.W. and Mwangi, J.G. 2004. Effects of the Co-operative Class Experiment Teaching Method on Secondary School Students' Chemistry Achievement in Kenya's Nakuru District. International Education Journal Vol 5(1) pp 26-36.

Watson, A. 2010. The Problem of Boys' Literacy Underachievement: Raising Some Questions Journal of Adolescent and Adult Literacy Vol 53 (5) pp 356 -361.

Welch, G.A. 2010. Using TOSRA to Assess High School Students' Attitudes toward Science after Competing in the First Robotics Competition. EYMSTE Vol. 6(3) pp 187-197. 
Wyss, R.(2002) Field Independent (Dependent Learning Styles and L2 Acquisition. The Weekly Column.

Zhang, L.F. 2004. Revisiting the Predictive Power of thinking styles for Academic Performance. Journal of Psychology: Interdisciplinary and Applied, Vol. 138 (4) pp 351 -370. 